\title{
Multiple Myeloma Involving Left Hemicranium
}

\author{
Jutty Parthiban ${ }^{1}$ Udaykumar B. ${ }^{1} \quad$ Sudeendra Reddy Peddireddy ${ }^{1}$ Balasubramaniam Prakash ${ }^{2}$ \\ Vighnesh Kandha Kumar ${ }^{2}$
}

${ }^{1}$ Department of Neurosurgery, Kovai Medical Centre and Hospital, Coimbatore, Tamil Nadu, India

2Kovai Medical Centre and Hospital, Coimbatore, Tamil Nadu, India

Address for correspondence Jutty Parthiban, MBBS, MCh, Department of Neurosurgery, Kovai Medical Centre And Hospital, 99 Avinashi Road, Coimbatore, Tamil Nadu 641014, India

Indian J Neurosurg 2022;11:274-276 (e-mail: juttyparthiban@gmail.com).
Abstract
Keywords
- Skull bone lesion
- Plasmacytoma
- Multiple myeloma

Multiple myeloma (MM) is a malignant neoplasm of bone marrow affecting plasma cells. It is commonly seen as multiple punched-out lesions in the skull bone as a characteristic feature. Its presentation as hemicranial involvement with intracranial extension is rare. A 46-year-old male presented with left side scalp swelling, prominent over parietal region. X-ray showed multiple punched out lesions involving left hemicranium. CT and MRI brain showed intracranial extension of lesion without brain parenchyma invasion. He was treated with biopsy of lesion followed by chemotherapy.
Multiple myeloma (MM) is a malignant disorder characterized by the proliferation of a single clone of plasma cells derived from $B$ cells in the bone marrow, which produces monoclonal protein (IgG, IgA, and light chain protein $\mathrm{K}$ or $\lambda$ are the most common). ${ }^{1,2}$ It accounts for approximately $1 \%$ of all malignant diseases and represents about $10 \%$ of hematologic malignancies. ${ }^{3}$ Bone involvement including skull bone causes osteolytic lesions and osteopenia, which leads to extensive skeletal destruction and consequent pathological fractures. ${ }^{4}$ The common clinical presentation is fatigue and bone pain (back or ribs), with or without associated fractures or infection and weight loss. In 15 to $30 \%$ of patients, ${ }^{5}$ the finding at presentation is hypercalcemia with concomitant renal insufficiency, caused by precipitation of monoclonal light chains in the collecting tubules. Other symptoms like hyperviscosity syndrome, compression of the spinal cord leading to radicular pain, soft-tissue deposits, or bleeding problems can be presented only in $10 \%$ of patients. In patients who are asymptomatic, the disease is incidentally discovered because of laboratory findings of anemia or hyperproteinemia. ${ }^{6}$ The pathogenesis of the bone lytic lesions in MM involves an imbalance between osteoblastic and osteoclastic functions. The osteoclastic activation is increased in MM, with bone reabsorption stimulated by the receptor activator of nuclear factor $\mathrm{K}-\beta$ ligand
(RANKL), which is overexpressed secondary to low levels of osteoprotegerin, the RANKL decoy receptor. ${ }^{7}$

We present a case of a 46 -year-old male patient presented with scalp swelling on left side, starting from parietal region and progressively increasing in size over 6 months. There was no history of recent trauma, fever, headache, or any other neurological impairment. On local examination, scalp swelling was observed involving left hemicranium, which was diffuse, firm to rubbery in consistency and with ill-defined borders.

On evaluation, CT brain showed multiple lytic lesions majorly involving the left side of the skull. MRI brain showed multiple osteolytic lesions over bilateral occipital region, and left temporal and parietal bone, with enhancing lesion in diploic space and minimal extradural soft-tissue extension with enhancement. PET CT showed multiple hypermetabolic regions over the skull ( - Fig. 1).

All routine blood investigations were within normal range. Protein serum electrophoresis showed M band 21.5\% (raised). Incisional biopsy from high parietal region showed sheets of monotonous cells, with eccentrically placed small round nuclei, clumped chromatin and scanty cytoplasm, which was suggestive of plasmacytoma.

He was started on chemotherapy with bortezomib and thalidomide. He developed grade III neuropathy due to which
DOI https://doi.org/ $10.1055 / \mathrm{s}-0041-1726603$ ISSN 2277-954X
(C) 2022. Neurological Surgeons' Society of India.

This is an open access article published by Thieme under the terms of the Creative Commons Attribution-NonDerivative-NonCommercial-License, permitting copying and reproduction so long as the original work is given appropriate credit. Contents may not be used for commercial purposes, or adapted, remixed, transformed or built upon. (https://creativecommons.org/licenses/by-nc-nd/4.0/).

Thieme Medical and Scientific Publishers Pvt. Ltd. A-12, 2nd Floor, Sector 2, Noida-201301 UP, India 


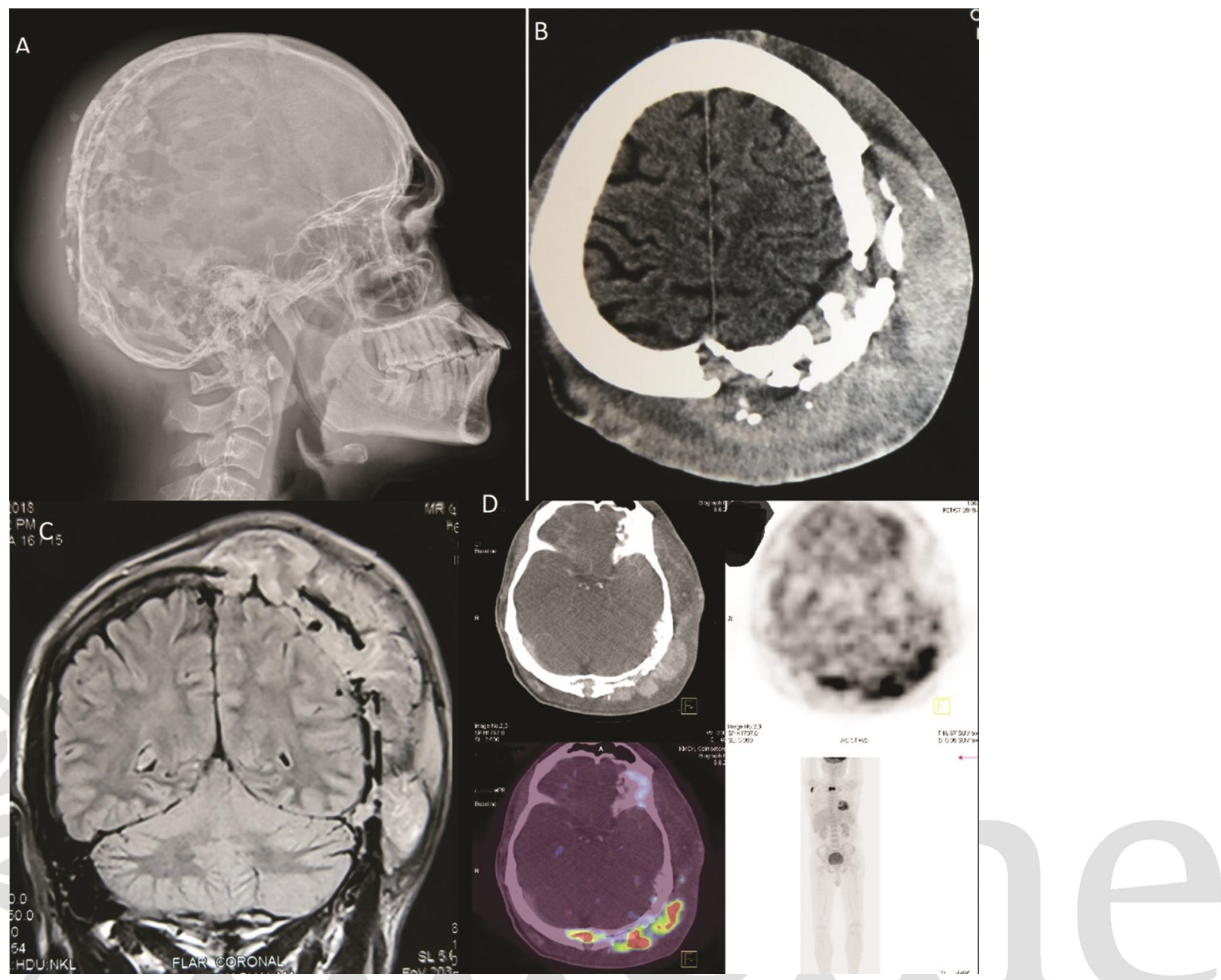

Fig. 1 (A) X-ray skull showing multiple osteolytic lesions occupying parietal and occipital region. (B) CT brain showing soft-tissue lesion in left parietal with underlying brain parenchyma apparently normal. (C) MRI brain showing enhancing lesion in diploic space with minimal extradural soft-tissue extension. (D) PET CT showing intensely hypermetabolic lytic lesions.

chemotherapeutic regimen changed to carfizomib-lenalidomide and dexamethasone. Follow-up PET CT showed good response to treatment with regression of lesion ( - Fig. 2).

Plasmacytoma is a solid tumor, which can present as solitary lesion or can be related to past or present MM. Solitary plasmacytomas of head and neck is rare. They can have an intraosseous growth pattern or can arise from within soft tissue such as the extramedullary plasmacytoma. In contrast to solitary plasmacytoma of the bone, extramedullary plasmacytomas rarely progress to MM. As in our case, whole left hemicranium is involved with intracranial extension without brain parenchyma involvement. ${ }^{8}$ The diagnosis of plasmacytoma is based on a radiologically solitary bone lesion, plasma cells in the biopsy specimen, less than $5 \%$ of plasma cells in bone marrow, less than $2.0 \mathrm{~g} / \mathrm{dl}$ monoclonal protein (M-protein) in the serum if present, absence of Bence Jones protein in urine, no evidence of hyperglobulinemia and hypercalcemia, and absence of anemia. Analyzing our case (bone lesion, M-protein in the serum, bone marrow plasmacytosis of $21.5 \%$, and related end-organ damage like anemia) supports the diagnosis of symptomatic myeloma. Plasma cell neoplasm is radiosensitive; therefore, local biopsy/debulking followed by radiotherapy had a good result on plasmacytoma. Once disease progresses to MM, prognosis is not as good as plasmacytoma and chemotherapy should be added. The potential for malignant systemic progression is higher for solitary plasmacytomas of bone than for extramedullaryplasmocytomas. ${ }^{9}$ Extramedullary localizations of myeloma originating from the cranial bone usually respond well to drugs (e.g., thalidomide, bortezomib, and lenalidomide) compared to central nervous system (CNS) myeloma. Our patient developed grade III neuropathy after bortezomib; hence, the regimen was changed to carfizomib -lenalidomide and dexamethasone. Disease regression was noted on follow-up PET-CT.

MM and plasmacytoma are very common and usually present as punctate or discrete lesion. Large hemicranial involvement is rarely seen. In spite of the size, chemotherapy is main line of treatment. 

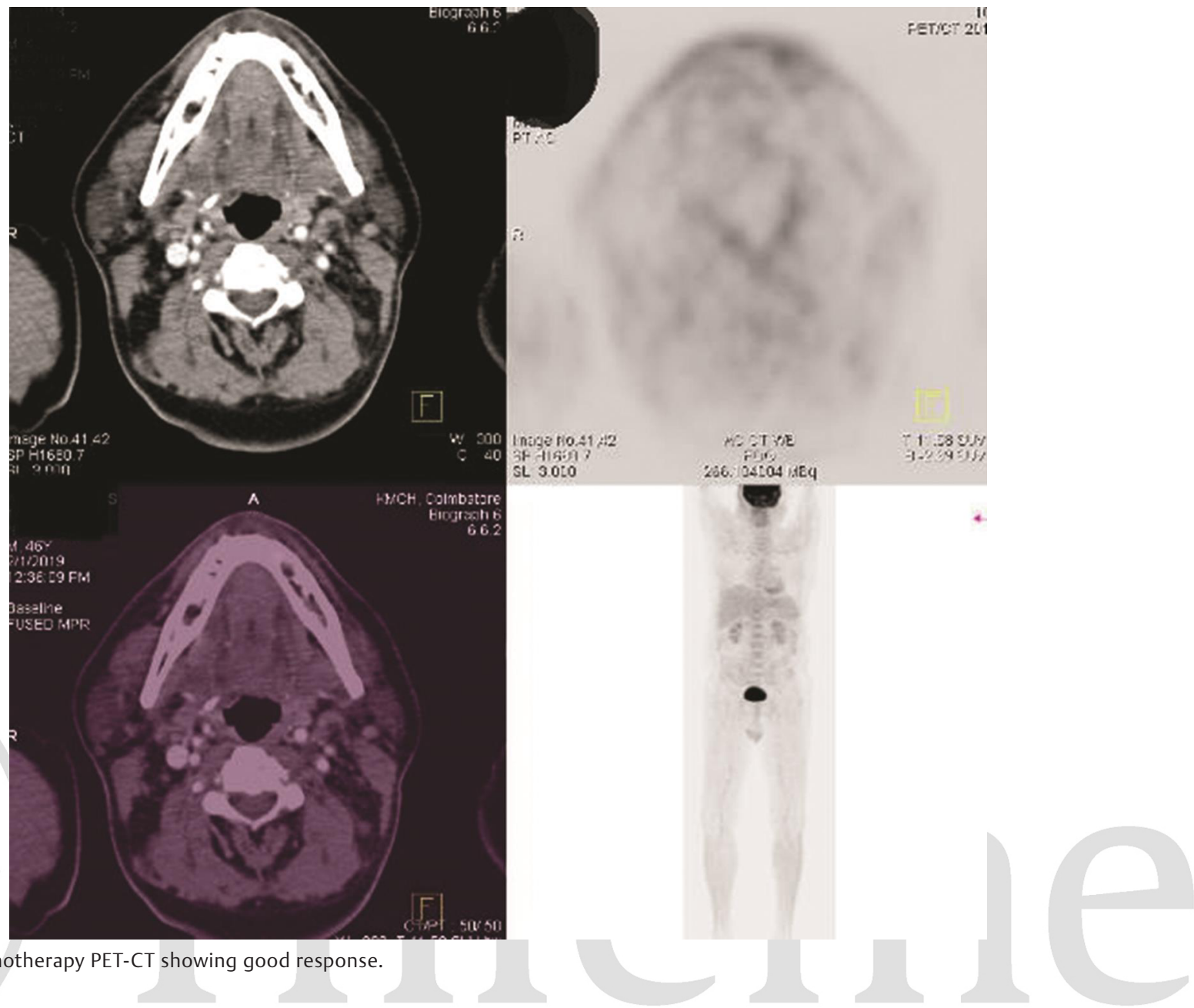

Fig. 2 Postchemotherapy PET-CT showing good response.

\section{Conflict of Interest}

None declared.

\section{References}

1 Kyle RA, Rajkumar SV. Criteria for diagnosis, staging, risk stratification and response assessment of multiple myeloma. Leukemia 2009;23(1):3-9

2 Kuehl WM, Bergsagel PL. Molecular pathogenesis of multiple myeloma and its premalignant precursor. J Clin Invest 2012;122(10):3456-3463

3 Muttaqin Z, Arita K, Uozumi T, et al. Vasospasm after traumatic subarachnoid haemorrhage: transcranial Doppler evaluation. Case report. Neurosurg Rev 1991;14(4):321-325

4 Bitelman VM, Lopes JAD de O, Nogueira AB, Frassetto FP, Duarte-Neto AN. "Punched out" multiple myeloma lytic lesions in the skull. Autops Case Rep 2016;6(1):7-9
5 Niesvizky R, Warrell RP Jr. Pathophysiology and management of bone disease in multiple myeloma. Cancer Invest 1997;15(1):85-90

6 Angtuaco EJC, Fassas ABT, Walker R, Sethi R, Barlogie B. Multiple myeloma: clinical review and diagnostic imaging. Radiology 2004;231(1):11-23

7 Roodman GD. Role of the bone marrow microenvironment in multiple myeloma. Journal of Bone and Mineral Research 2009;17(11):1921-1925

8 Senapati SB, Mishra SS, Dhir MK, Das S, Tripathy K. A case of multiple myeloma presenting as scalp swelling with intracranial extension. J Neurosci Rural Pract 2013;4(4):445-448

9 Kumar S, Jain AP, Waghmare S. Multiple cystic swelling: initial presentation of multiple myeloma. Indian J Med Paediatr Oncol 2010;31(1):28-29 